\title{
"One Ancient Greek and One Mythic Bird: The Cunning of the Engineer"
}

\author{
Philip J. Chmielewski, S.J. \\ Loyola Marymount University
}

Engagement in life-long learning (ABET) can be fostered by utilizing resources drawn from (a) classical Greek literature and (b) modern ethnography. Life-long learning does not simply happen because a person lives or even lives long. The habit of the learning that accompanies the stages of one's life and one's career must be acquired. In this paper the focus is directed to the shrewd, problem-solving intelligence specific to engineering. When they design a project, engineers undertake a set of coordinated activities. They follow a combination of particular protocols so that, for example, dangers are obviated and efficiency attained. Engineers also negotiate their design activities within several ranges of constraints, for example, budgets, timetables, and the limits of materials. In addition, they engage imaginative creativity, because project specificity invites it or because project singularity demands it. ${ }^{7: 28}$

Life-long learning requires the extension of curiosity into new areas. Engineers become free for such an extension, if they first recognize their own capacity. To examine the same intelligence deployed in alien settings stimulates such a self-appropriation. If engineers visit an apparently removed context, they may then discover there and, as a consequence, firmly grasp the features of their own intelligence. A first step in recognizing the engineer's problem-solving capacity is a study of "cunning intelligence" in the ancient Greek world. In particular, an examination of the endlessly alert mind of Odysseus can assist the students in self-recognition. At a minimum, Odysseus is a merely moral exemplum that if one fails in life-long learning, life ends. More fully understood, the myth of Odysseus shrewdness' frees students to initiate their own habit of acquiring knowledge.

Many college students are relatively familiar with the mythic figure of Odysseus because they have heard, at least in some form, of his war experiences or his travel adventures. Less familiar, and quite significant for engineers, is the signal, constitutive trait of Odysseus' character as Homer's poems present him. Homer creates Odysseus as repeatedly manifesting "metis." In Greek culture, "metis" as a human trait combines intelligence, trickery and the practice of technology.

When early in his travels Odysseus encounters the Cyclopes, the poem makes clear the difference between the mind of the traveler and the world of the giants. The Cyclopes do not know shipbuilding, cannot visit other regions, and do not build cities. (Odyssey 9:125-130) When the Greeks, in order to have a chance to save their lives, destroy the eye of the imprisoning Cyclops, Homer alludes to the technologies of shipbuilding and iron work. ${ }^{11: 16}$

Odysseus' divine patron is Athena who serves as his protector and who takes delight in

"Proceedings of the 2003 American Society for Engineering Education Annual Conference \& Exposition Copyright (C) 2003, American Society for Engineering 
the exploits and character of Odysseus. Athena's hidden mother was, in fact, named Metis. Athena, the gray-eyed goddess, repeatedly aids Odysseus because she is taken with this mortal whose character is so like her own. Mythic tales together constitute a body which explores human actualities. Tales concerning the several gods and various heroes explore the different dimensions of human experience. Zeus, Apollo, and Hermes offer presentations of other dimensions of human rationality. Athena's intelligence is the dispassionate exercise of reasoning for practical ends: not only shipbuilding and metalworking, but also weaving, carpentry, and most importantly, the creation of cities on the basis of edifices and systems. To understand this about Athena, is to understand the specificity and significance of Odysseus' "metis".

Odysseus, Homer carefully notes, after the Olympians had arranged for his freeing from confinement on Calypso's island, constructs his own boat. It is not a raft; it is a ribbed boat that required planning and careful execution. (Odyssey 5:244-231) It is the sort of tight work that Athena upholds. And, for the Greek mind, it is the technology that makes cities, centers for the exchange of goods and ideas, possible. A ship is a system tool that enables the mind and the common life to move out and learn. ${ }^{13: 121-122}$

Building a boat, however, is only one example of "metis" at work. Cunning intelligence must be carefully distinguished from craft activity. "Metis" involves sizing up a problem, setting a goal, and securing the execution of each directed step. Such planning and one specific form of execution required Odysseus' metis when he had to face the plague of suitors and, thereby, could restore his city Ithaca.

The wiles and cleverness of Odysseus are manifest not only in skills, construction, and planning, but also in words. In the two Homeric epics, this mythic hero is described sixty-six times as "polymetis," "rich in plans." All but three of these times, this trait is highlighted in connection with Odysseus' activity of skillful, effective speech. ${ }^{11: 14, \text { n. } 51}$ The engineering cleverness becomes manifest first in words, then in project. Readily exemplifying this are the persuasive efforts of nineteenth century engineers, most famously John Roebling, in securing approval for suspension bridges. ${ }^{18: 162-164}$

Whether confronted by a doubting, crusty client or with the partially as yet undetermined milling qualities of a new alloy, the engineer deploys his skills in terms of persons and materials that are varied, varying, and active. The man Odysseus becomes heroic insofar as he confronts a many-sided, demanding, and rapidly changing set of environments. In order to attain both his proximate and long-range goals, he must exercise his control, a control that derives from an intelligence more varied and more agile than the forces he faces. ${ }^{8: 5-6}$ The agility of "metis", the capacity of engineering intelligence, must not only flex in the face of multiple and often unexpected demands but also must demonstrate a greater malleability and a more rapid suppleness than that evidenced by the other factors in the situations faced.

The Homeric world of Odysseus marks a shift from the world of Agamemnon, the warrior king and of Achilles, the warrior favored by the gods. The cultural shift that takes place is a significant vector in the reflection which the epic poem examines. The "metis", the cunning intelligence, of Odysseus confronts not just problems, but a new web of values. Homer brings the 
audience to see a shift from heroism to a responsibility within history. The poet has turned from the world where praise focused on the destroyers of the city to a new culture where the momentous activity was the establishment not of palaces and encampments but of cities and of the space for common life.

With respect to the venture where one attempts to lead students to the habit of life-long learning, the Odyssean material runs into the difficulty that the hearers of the tales may insulate themselves from engagement, if they see Odysseus as a prince or as historically distant. In these cases, rank or temporal difference can hinder the students from learning about the peculiar character of "metis" in their own professional activity.

A mythic figure from another cultural zone finds a home in the poetic traditions of the northwest coast of North America. A shift to the narratives that present this mythic figure requires a mental realignment from literate to oral society. The ancestral stories offered within the cultures of several Native American peoples from today's British Columbia present the figure of Raven. While Odysseus emerges in the pre-classical Greek world, Raven emerges in the tales of the Haida, Tlingit, Tsimshian, Heiltsuk, Nuxalk and other inhabitants of southeastern Alaska and northwestern British Columbia. Both are travelers. Both are foreigners. Raven, like Odysseus, confronts a world that undergoes profound and sweeping changes. To take up the Raven myths is to attend to a figure outside of any history and apart from distinctions of rank, even apart from god-human-animal distinctions. Raven uses his intelligence as a rebel and also as a shaper of laws. ${ }^{14: 11}$

Since Raven tales are likely less familiar to many students, here is a brief excerpt from one tale about the origin of fire.

Again ... [Raven] went on, and the people began to multiply on the earth. However, they were distressed because they had no fire to cook their food and to warm themselves in the winter; and Giant [i.e., Raven] remembered that they had fire in the village of the animals.

... [H] e sent . . the Sea gull to carry a message to the people . . . "A good-looking young chief will come soon to the people to have a dance in your chief's house." ... Then Giant caught a deer and skinned it. At that time the deer had a long tail, like a wolf's tail. Giant tied pitch wood to the long tail of the deer. ... Then all the people entered. They built a large fire, larger than it had been before, and the great house of the chief was full of his tribesmen.

The Deer entered at the door. He looked around, and entered leaping and dancing, and went around the large fire. ... Finally he struck his tail over the fire, and the pitch wood on his tail caught fire. He ran out with the firebrand on his tail and swam on the water. ... The people tried to catch the Deer, intending to kill him. ... [H] e went ashore quickly, struck a fir tree with his tail, and said, "You shall burn as long as the years last." For that reason the deer has a short black tail. $^{3: 63}$

Raven is not a creator, but rather a transformer. He takes the substances and forces of creation and fashions a world in which human persons come to live. The mythic raven, through

"Proceedings of the 2003 American Society for Engineering Education Annual Conference \& Exposition Copyright (C) 2003, American Society for Engineering Education" 
inventiveness and imagination, repeatedly supplies human needs. Raven does not create the sun,

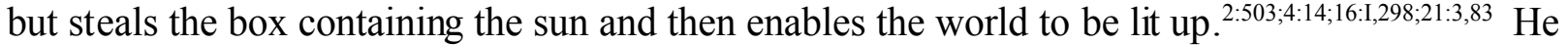
distributes fresh water. ${ }^{4: 26 ; 21: 83 ; 5: 302}$ Fire he obtains, preserves, and distributes. ${ }^{4: 32 ; 21: 11,83}$ Raven arranges for tidal cycles so that along the beach persons can obtain shellfish. ${ }^{21: 8,121}$ In addition, he also teaches people the processes both for obtaining and for processing fish foodstuffs. For example, in order that humans can fish in the zone beyond the shelter of rivers and bays, he provides the halibut hook. ${ }^{1: 11 ; 21: 84}$ From Raven, humans learn how to catch eulachon fish and render the oil from it. ${ }^{16: 1,89 ; 21: 11}$ Concerning the mythic and culture-central salmon, Raven offers guidance on freezing and storing this fish. ${ }^{21: 89}$

Like Odysseus Raven too displays his cleverness through his skill in words. (ABET, "effective communication") Thus he repeatedly achieves a critical step in one of his schemes by persuading another to carry out a part of the plan, often at the other's own cost. Clear enough to many engineers is that their design work is not simply the cranking out of a calculated craft; needful, rather, is a fresh view of the structures and processes and materials - a view that can guide them to service. Clear enough to many engineers working as managers is that effective presentations to clients, boards, and others requires a fresh view of the forces and processes that shape and stress these individuals. Elihu Thomson's career in the electrical industry gives evidence of this wide-ranging inventiveness. ${ }^{6: 7,14}$ What student engineers must learn about their own clever intelligence is that an attention to their words, to their rhetorical suasion, to their discursive engagement is a ready part of their own work. Moreover, their work with words, proficiently appropriated as part of their own professional activity, may well assist them in sidestepping some of the impasses that arise in the course of their careers. Most significantly, the work with words rapidly reminds young engineers of the civic dimension of their work. Not simply the end result of their efforts -widget, subroutine, bridge truss - but their very work, working, and collaborating are word-borne, and thus civic.

Important to note is that repeatedly in these exploits the texts record how Raven assesses a situation, then devises a clever plan, and only then carries it out. Moreover, as he executes his plan, most often Raven himself must change. ${ }^{12: 160}$ He loses his beak or changes his color or alters his size and promptly puts on or takes off a disguise. In similar ways, on the path to his goal, Odysseus would don a disguise either in costume or narration. Thus, the mythic pair must exercise their "metis" even in terms of themselves. So, as engineers reflect on their specific engineering intelligence, they can come to see that this shrewdness has a reciprocal power: as they work to change a system, circuit, process, or structure, they also are changing themselves. ${ }^{13: 132}$ Or can. If they do not, indications of ennui may emerge; cynicism may be brokered; "real living" becomes disjoined from work.

How might it be understood that engineers themselves come to change because of the process of their own cunning activity? One pattern was indicated above, where the mythic figures exercise "metis" effectively because they are more rapid than the quick forces they face. Such rapidity is gained by way of a comprehensive perspective. Assigned to a defined task to be approached objectively, the engineer still can recognize the desire to understand how this work fits into the larger picture. Engaged in a series of routinized, narrowed and manageable assignments, the engineer nevertheless can recall previous projects; out his/her memory arise

"Proceedings of the 2003 American Society for Engineering Education Annual Conference \& Exposition Copyright (C) 2003, American Society for Engineering Education" 
questions. In this light, life-long learning means that engineers grow more comprehensive in their grasp because their intelligence takes delight in its own exercise. Their intelligence draws them into a breadth because they themselves must develop not only as persons but also as active members of civic space. They see more widely and consequently can choose, decide, and act promptly as well effectively.

Homer, as was pointed out, moves Odysseus from the realm of heroism to the time of responsible history. Likewise, the cycle of Raven adventures move to the end of the mythic age, to the point where Raven has readied all so that the lives of humans and the unfolding of their story can begin. 12:176 What have these two incessant travelers have to do with responsible action within history? Mythic travel - whether Greek or avian -- is an emblem for blind variation. ${ }^{22: 241-244}$ From the elements encountered, the mythic figures select options for themselves, for their families and friends, and for the common spaces they establish. Their life-long learning makes possible both the perspective that secures breadth of knowledge and swift, apt decision. Mythic travel at the border upon history indicates that such variation and selection lead to the establishment and maintenance of a common space for human action. In fact, that the myths and their retelling preserve and propagate the selected options for common life parallels the growth process of engineering knowledge. ${ }^{22: 245}$

While Odysseus' winding words and Raven's disguises signal the inner transformation that accompanies the external work of "metis", they also make the myths' audience aware of the possible, deep harms that "metis" can cause. "Metis" has a doubleness: it can benefit home and society, or it can deceive for the sake of merely personal ends: honor for Odysseus, food for Raven. The Trojan horse (Odyssey, Books IV, VIII, XI and Virgil's Aeneid, Book II) -- within which Odysseus was the commander - exemplifies "metis" as crafting a designed tool within a social framework and "metis" as working to deceive. Some stories about Odysseus (e.g., Palamedes) and many in the Raven collection (e.g., Cormorant: ${ }^{3: 92-93}$ ) report the harm caused by their shrewd planning. Such tales make it possible for young engineers to study the potential misuse of intelligence (ABET). Contemporary engineers through the myths can come to understand this loaded doubleness of their own cunning intelligence.

Those forces that threaten human life constitute the stark background which emphasizes the weightiness of the engineering intelligence. While the Greek epic tradition offers the story of the cunning traveler confronting the one-eyed, uncivilized Cyclops, Raven must defeat the Man with One Eye, a shaman who uses his spirit powers to harm others. ${ }^{21: 95}$ Whereas Homer shows us how Odysseus carefully crafts a boat, Raven teaches the people about canoes. ${ }^{21: 84}$ Boats and canoes represent human inventive intelligence turning the sea to human purposes. The sea is a force -- and represents all forces -- that can hinder or end the travel of persons and human life. What both mythic figures are about is overcoming or staying the forces of death by means of cultural constructions. Odysseus evades both outright physical death and also death-analogues: the drugged loss of memory and bitter homelessness. ${ }^{19: 17}$ For the sake of human beings, lest they face flood, cold, thirst, and famine, Raven provides systems, sources, and devices whereby persons may maintain their individual and common lives. ${ }^{17: 92}$

How do the two epic agents carry out their exploits? Obviously, on the strength of their

"Proceedings of the 2003 American Society for Engineering Education Annual Conference \& Exposition Copyright (C) 2003, American Society for Engineering Education" 
particular intelligence, their cunning. What marks this cunning? Its suppleness. Yet one must carefully note that this suppleness is not simply a character trait. Rather, it is a means of reflection developed within a specific, encompassing framework. Odysseus does not simply sail several ships; he navigates between worlds. Raven does not travel endlessly, he moves across charged borders. In Raven's case, he moves between the worlds of matter (sea, air, forest, shore), humans, animals, and spirits. In addition to Odysseus' encounter with foreign peoples and natural elements, familiar in the West are the gods with whom he must struggle or negotiate. But for the engineer today what does his/her cunning intelligence have to do with gods and spirits? Let these mythic contenders represent the unseen, actual charges, potentials, stresses, loads, and forces that are the work of the world. Then the "metis" of the engineers is a negotiation with and suasion of these invisible forces borne within the materials of a project on behalf of a human community.

Earlier, the civic range into which "metis" works was examined. "Metis" also works within a particular "cosmic" range. What the Olympian structure or the Native American spirit world as cosmological frameworks for "metis" help students to see is that their calculations, codes, drafts, and submittals do not automatically enable them to subject the world to their control; but, rather, make it possible for them to work within that world of materials and forces. Further, the myths can lead them to see that the exercise of their designing intelligence necessarily and only re-shapes the interplay of these forces. Their objective pursuit of a path for working with momenta, strains, and resistance can bring engineers to attend to the limits inherent in a particular project and to the potentials available when the perspective is widened. Beyond engineering imagined as a pursuit over against environmental constraints, to engineer is to remake a world. Through this world range forces often invisible, latent and potent that continue to work in it. "Metis" acts within an encompassing framework that is cosmic -- that is, widely arranged -- and mundane - ordinarily impinging.

The activity of the engineer is like that of Odysseus because the mythic hero uses his skills as well as the constraints of situations to make surfaces appear: the surface of a hull and the surface of a sail. He negotiates the surface of the conquered sea while his wife, Penelope, who shares his characteristic intelligence, under duress makes the surface of her weaving become manifest. ${ }^{15: 70-71}$ The engineer today makes surfaces appear: the face of an arched dam, a crowned pavement with shoulders, an aircraft wing, a LCD screen that presents ordered data.

The status and significance of the surface-shaping that results from the exercise of "metis" is clarified upon a further examination of the Tsimshian culture, a key vehicle for Raven mythology. Containers - boxes, bowls, houses, blankets, lineage tales -- are prominent features of Tsimshian culture and in the Raven tales. Something is real insofar as it is contained. Raven and skilled First Nations craftspeople today - shape reality; they craft reality insofar as they put together containers. Cunning intelligence fabricates containers when it fashions and joins surfaces. In the Tsimshian world, the universe itself, as fashioned by Raven, is a container for light. ${ }^{17: 42}$ On the one hand, Odysseus' cunning creates surfaces that are visible, that catch the light; on the other hand, Raven utilizes containers so that light emerges. In both cases, the light makes possible and serves the world of human interaction. Surfaces are effective but fragile. Containers shield and convey valuables to be shared. In both these mythic cultures, shrewd intelligence crafts those fragile artifacts that must, against the eroding forces, ever be carefully remade. That intelligence also enables light to emerge, that is, "metis" enables other persons to 
find the light so that they too can use their eyes and mind. That both mythic figures shape a civil world can assist engineers in comprehending the wider range of professional responsibility that their shrewd intelligence governs. Their imagination shapes a world for others and also for the sake of the independent activity of those persons.

Both of these sets of mythic tales examine the concept of "global context" (ABET) in terms of cross-cultural encounter. The exploits and travels of Odysseus emerge from a Hellenic consciousness growing more alert to other societies. The people of Raven pursued technological advances as they encountered arriving Asians and Americans. The engineer must be adept in traversing borders so that ongoing learning may be adequate to contemporary projects. On the one hand, engineers must design in coordination with the ever-shaping local culture, ${ }^{18: 102-105}$ on the other, they must be alert to the expressed and unexpressed wishes of clients, colleagues, consumers, and citizens in the perhaps-difficult-to-grasp society where they serve.

The two bodies of these mythic stories - from the ancient Mediterranean world and from the northwest Pacific coast, themselves are tools that exercise "metis." That is, the telling and retelling of these two sets of tales remind and sway other transformers, other fashioners of the human built and crafted spaces - whether interstates or internet - that their efforts move beyond mere necessity. Engineers, on the basis of their cunning inventiveness, like Odysseus engage in normal design or, like Raven, pursue radical design. ${ }^{22: 7-9}$ Engaged in either practice, they exercise a particular imagination. The work of this cunning enables history to emerge. That is, the proper work of engineers constrains the forces of death so that people can act and brings light so that people can undertake their own activity and even reflect upon it. Engineers can create a space that is both civil and cosmic: a space that elicits free contributions to common ends and a space that remains attentive to the hidden, potent, unmasterable forces. As they fashion a civic, cosmic space that acts as a container for the entire variety of human light, of personal intelligence, engineers themselves can come to hold the habit of life-long learning. Beyond the iterated control of ever novel bodies of information, life-long learning is a habit where engineers come to see their place together with others on the fragile surface of discourse: public word and common project.

1. Franz Boas. Bella Bella Texts. New York: Columbia University Press, 1928.

2. Indian Myths and Tales from the North Pacific Coast of America. Edited and annotated by Randy Bouchard and Dorothy Kennedy. Translated by Dietrich Bertz. Vancouver: Talon Books, 2002.

3. $\quad$ Tsimshian Mythology. $31^{\text {st }}$ Annual Report of the Bureau of American Ethnology. Washington, D.C.: Government Printing Office, 1916.

4. ․ Tsimshian Texts. Bulletin 17. Washington, D.C.: Government Printing Office, 1902.

5. Robert Bringhurst, editor and translator. Being in Being: The Collected Works of a Master Haida Mythteller, Skaay of the Qquuna Qiighawaay. Lincoln: University of Nebraska Press, 2001.

6. W. Bernard Carlson. Innovation as a Social Process: Elihu Thomson and the Rise of General Electric, 1870-1900. Cambridge: Cambridge University Press, 1991.

"Proceedings of the 2003 American Society for Engineering Education Annual Conference \& Exposition Copyright (C) 2003, American Society for Engineering Education", 
7. Michael Davis. Thinking Like an Engineer: Studies in the Ethics of a Profession. New York: Oxford University Press, 1998.

8. Marcel Detienne and Jean-Pierre Vernant. Cunning Intelligence in Greek Culture and Society. Translated by Janet Lloyd. Chicago: University of Chicago Press, 1978.

9. Francois Hartog. Memories of Odysseus: Frontier Tales from Ancient Greece. Translated by Janet Lloyd. Chicago: University of Chicago Press, 2001.

10. Bernd Heinrich. Mind of the Raven: Investigations and Adventures with Wolf-Birds. New York: Harper Collins, 1999.

11. Ingrid E. Holmberg, "Sign of Metis" Arethusa: 30:1 (1997):1-33.

12. Allan Jensen. "A Structural Approach to the Tsimshian Raven Myths: Levi-Strauss on the Beach." Anthropologica Series 2, vol. 22 (1980): 159-186.

13. John Law. "Technology and Heterogeneous Engineering: The Case of Portuguese Expansion" 111-134 in The Social Construction of Technological Systems: New Directions in the Sociology and History of Technology edited by Wiebe E. Bijker, Thomas P. Hughes, and Trevor J. Pinch. Cambridge: The MIT Press, 1987.

14. Claude Levi-Strauss. "Preface" in The Raven Steals the Light by William Reid. Seattle: University of Washington Press, 1996.

15. Indra Kagis McEwen. Socrates Ancestor: An Essay on Architectural Beginnings. Cambridge: MIT Press, 1993.

16. T.F. McIlwraith. The Bella Coola Indians. 2 volumes. Toronto: University of Toronto Press, 1992.

17. Jay Miller. Tsimshian Culture: A Light Through the Ages. Lincoln, Nebraska: University of Nebraska Press, 1997.

18. Henry Petroski. Invention by Design: How Engineers Get from Thought to Thing. Cambridge: Harvard University Press, 1996.

19. Pietro Pucci. Odysseus Polutropos: Intertextual Readings in the Odyssey and the Iliad. Ithaca: Cornell University Press, 1987.

20. John Scheid and Jesper Svenbro. The Craft of Zeus: Myths of Weaving and Fabric. Translated by Carol Volk. Cambridge: Harvard University Press, 1996.

21. John Swanton. Tlingit Myths and Texts. Washington, D.C.: Government Printing Office, 1909. Reprint: St. Clair Shores, Michigan: Scholarly Press, 1976.

22. Walter G. Vincenti. What Engineers Know and How They Know It. Baltimore: Johns Hopkins University Press, 1990.

PHILIP J. CHMIELEWSKI, S.J. holds the Sir Thomas More Chair of Engineering Ethics in the College of Science and Engineering of Loyola Marymount University in Los Angeles.

"Proceedings of the 2003 American Society for Engineering Education Annual

Conference \& Exposition Copyright (C) 2003, American Society for Engineering

Education" 